\title{
POLÍTICAS PÚBLICAS PARA EDUCAÇ̃̃O PROFISSIONAL: DÉCADA DE 1990 E A DESVINCULAÇÃO DO ENSINO MÉDIO E TÉCNICO
}

\author{
POLÍTICAS PÚBLICAS PARA EDUCACIÓN PROFESIONAL: DÉCADA DE 1990 \\ Y LA DESVINCULACIÓN DE LA ENSEÑANZA MEDIA Y TÉCNICA
}

\author{
PUBLIC POLICIES FOR PROFESSIONAL EDUCATION: THE 1990s AND \\ THE SEPARATION OF SECONDARY AND TECHNICAL EDUCATION
}

\author{
Laurinda Ines Souza de MORAES ${ }^{1}$ \\ Silvia Sell Duarte PILLOTTO ${ }^{2}$ \\ Jane Mery Richter VOIGT ${ }^{3}$
}

\begin{abstract}
RESUMO: O presente artigo objetiva analisar as políticas públicas para a educação profissional, em especial da década de 1990, com relação à desvinculação do ensino médio e técnico. O campo de pesquisa foi o Instituto Federal de Santa Catarina (IFSC) Campus Jaraguá do Sul. De abordagem qualitativa, a pesquisa contou com análise de entrevistas e análise documental, que deram suporte à interpretação de documentos institucionais, leis, decretos e portarias relacionados à educação profissional na década de 1990, principalmente o Decreto n. ${ }^{\circ}$ 2.208/1997. Como referencial de análise dos dados contamos com a Análise de Conteúdo, referendada por Bardin (2011). Os resultados obtidos por meio das entrevistas a respeito da reforma da educação profissional, da implementação do Decreto 2.208/97 e da extinção dos cursos técnicos integrados ao ensino médio apontaram que essa política pública contribuiu de maneira significativa para a diminuição da oferta de vagas públicas e gratuitas do ensino médio na instituição. As determinações da reforma da educação profissional acarretaram a queda da qualidade do ensino em virtude da extinção da integração entre educação geral e educação profissional. As políticas públicas deveriam também responder aos desafios de atender a duas demandas: o acesso ao trabalho e a continuidade dos estudos.
\end{abstract}

\footnotetext{
${ }^{1}$ Mestre em Educação pela Universidade da Região de Joinville UNIVILLE. Possui Especialização em Educação Profissional Integrada à Educação Básica na Modalidade de Educação de Jovens e Adultos pelo Instituto Federal de Santa Catarina. E-mail: laura@ifsc.edu.br

2 Pós-Doutora no Instituto Estudos da Criança - IEC na Universidade do MINHO - UMINHO, Braga/Portugal em 2007/2008. Professora titular nos cursos de Artes Visuais e Pedagogia na Universidade da Região de Joinville - UNIVILLE e no Programa de Pós-Graduação - Mestrado em Educação; Pesquisadora e Coordenadora de Núcleo de Pesquisa em Arte na Educação - NUPAE, possui experiência nas áreas de Artes, Gestão, Currículo, Avaliação; Infância e Arte/Educação. Avaliadora do INEP, atua nos seguintes níveis da educação: educação superior e pós-graduação. Autora de vários livros publicados, desenvolve formação continuada e consultoria nas áreas citadas. E-mail: pillotto0@gmail.com

${ }^{3}$ Doutora em Educação, área de concentração Psicologia da Educação pela Pontifícia Universidade Católica de São Paulo - PUC-SP (2012). Mestre em Educação na linha de pesquisa Educação Matemática pela Universidade Federal do Paraná-UFPR (2004). Licenciada em Matemática pela Fundação Educacional da Região de Joinville - FURJ (1991). É professora titular da Universidade da Região de Joinville-UNIVILLE, atuando no Programa de Pós-Graduação - Mestrado em Educação, em cursos de graduação e como pesquisadora e coordenadora do Núcleo de Pesquisa em Arte na Educação - NUPAE. E-mail: janevoigt@terra.com.br
} 
PALAVRAS-CHAVE: Políticas públicas. Educação profissional. Ensino médio. Educação profissional.

RESUMEN: El presente artículo objetiva analizar las políticas públicas para la Educación Profesional, en especial de la década de 90 con relación a la desvinculación de la Enseñanza Media y Técnica. El campo de investigación fue el Instituto Federal de Santa Catarina - IFSC - Campus Jaraguá do Sul. De abordaje cualitativo, la investigación contó con análisis de las entrevistas y el análisis documental, que dieron soporte a la interpretación de documentos institucionales, leyes, decretos y porterías, relacionados a la Educación Profesional en la década de 1990, principalmente el Decreto 2.208/1997. Como referencial de análisis de los datos contamos con el Análisis de Contenido, refrendada por Bardin (2011). Los resultados obtenidos por medio de las entrevistas a respecto de la reforma de la Educación Profesional, de la implementación del Decreto 2.208/97 y la extinción de los Cursos Técnicos integrado a la Enseñanza Media, apuntaron que esta política pública contribuyó de manera significativa para la disminución de la oferta de vacantes públicas y gratuitas de la Enseñanza Media en la Institución. Las determinaciones de la Reforma de la Educación Profesional acarrearon la caída de la calidad de la enseñanza en virtud de la extinción de la integración entre educación general y educación profesional. Las políticas públicas deberían también responder a los desafíos de atender dos demandas: el acceso al trabajo y la continuidad de los estudios.

PALABRAS CLAVE: Políticas públicas. Educación profesional. Enseñanza media. Educación profesional.

ABSTRACT: The aim of this article is to analyze the public policies for Professional Education, especially in the 1990s regarding the separation of Secondary and technical education. The research field was the Federal Institute of Santa Catarina - IFSC Jaraguá do Sul Campus. From a qualitative perspective, the research included analysis of interviews and documentary analysis, which supported the interpretation of institutional documents, laws, decrees and ordinances related to Professional Education in the 1990s, in particular, Decree 2.208 / 1997. Content Analysis, endorsed by Bardin (2011), was used as a reference for data analysis. The results obtained through the interviews regarding the reform of Professional Education, the implementation of Decree 2.208 / 97 and the elimination of Technical Courses integrated to Secondary Education, indicated that this public policy significantly contributed to reducing the number of public and free of charge vacancies for Secondary Education at the institution. The specifications for the Professional Education Reform led to a reduction in the quality of education due to the elimination of integration between general education and professional education. Public policies should also respond to the challenges of meeting two demands: access to work and continuity of studies.

KEYWORDS: Public policies. Professional education. Secondary education. Professional education. 


\section{Introdução}

Este artigo se propõe a discutir aspectos das políticas públicas para a educação profissional na década de 1990 e sua desvinculação entre o ensino médio e técnico. O objetivo da pesquisa foi identificar os impactos da reforma da educação profissional na Unidade Jaraguá do Sul da Escola Técnica Federal de Santa Catarina (ETF/SC), atual Instituto Federal de Santa Catarina (IFSC) - Campus Jaraguá do Sul.

A investigação permitiu verificar como se deu o processo de implementação das políticas públicas para a educação profissional (Decreto n. ${ }^{\circ}$ 2.208/97) no Campus Jaraguá do Sul do IFSC. A reflexão ficou por conta dos seguintes questionamentos: como se deu o processo de desvinculação entre os ensinos médio e técnico mediante o Decreto n. ${ }^{\circ}$ 2.208/97? Quais foram os impactos na ETF/SC, unidade Jaraguá do Sul, atual IFSC - Campus Jaraguá do Sul?

Como referencial para análise utilizaram-se a Lei n. ${ }^{\circ}$ 9.394/96 (BRASIL, 1996), o Decreto n. ${ }^{\circ}$ 2.208/97 (BRASIL, 1997a), a Portaria n. ${ }^{\circ}$ 646/97 (BRASIL, 1997b) e demais documentos referentes à reforma da educação profissional na década de 1990. Além dos documentos oficiais usaram-se como suporte teórico obras de autores que discutem a educação profissional no Brasil, dentre os quais se destacam: Lima Filho (2002), Frigotto (2003; 2006), Frigotto, Ciavatta e Ramos (2005) e Kuenzer (2002).

O campo de pesquisa é uma antiga Unidade de Ensino Descentralizada de Jaraguá do Sul da Escola Técnica Federal de Santa Catarina (UnED/JS da ETF/SC), localizada no município de Jaraguá de Sul, estado de Santa Catarina. A coleta de dados foi realizada por meio de entrevistas semiestruturadas com nove educadores da referida instituição. Para as entrevistas selecionaram-se professores efetivos, de matrícula mais antiga, que vivenciaram efetivamente a implementação da reforma da educação profissional por meio do Decreto n. ${ }^{0}$ 2.208/97, a desvinculação entre ensino médio e técnico, na instituição pesquisada.

Para análise da política educacional recorreu-se às "abordagens do ciclo de políticas", proposto por Stephen Ball, que no Brasil é estudado por Mainardes (2006). De acordo com esse referencial, as políticas não são simplesmente implementadas, mas reinterpretadas no contexto da prática, e a compreensão da sua trajetória envolve a análise de cinco diferentes contextos: influência, produção do texto, contex to da prática, resultados/efeitos e estratégia política. Isso significa que as políticas educacionais não são construídas de maneira homogênea e simples, meramente refletindo os interesses do 
capital. Elas são, na verdade, o resultado de um intenso embate entre os anseios capitalistas e forças contrárias.

Dessa forma, para analisar as políticas implementadas por determinado governo, é fundamental refletir sobre as "questões de fundo", que estão relacionadas ao modo como as escolhas são feitas, que caminhos são traçados para sua implantação e os modelos de avaliação aplicados. Essas questões estão ligadas às concepções de Estado e política, em uma sociedade e num período histórico determinado (HÖFLING, 2001).

Para a análise das entrevistas, utilizou-se o referencial de Análise de Conteúdo de Bardin (2011). Após a transcrição das entrevistas, foi usada a categorização com base nas temáticas levantadas nas falas dos entrevistados: “implementação da política pública educacional" e "ensino médio profissional e propedêutico".

A Análise de Conteúdo trabalha com a palavra, permitindo de forma prática e objetiva produzir inferências do conteúdo da comunicação de um texto replicáveis ao seu contexto social. Ao empregar a análise de conteúdo nas entrevistas, o texto passa a ser um meio de expressão do sujeito, em que o pesquisador busca categorizar (tematizar/conceituar) as unidades de texto (palavras ou frases) que se repetem e/ou se contrapõem, inferindo uma expressão que as representem (BARDIN, 2011).

\section{A reforma da educação profissional: desvinculação entre ensino médio e técnico}

O processo de reestruturação do Estado e da economia, sob o viés neoliberal, posto em curso na década de 1990, colocou em prática uma agenda de desenvolvimento sob inspiração de agências internacionais como o Fundo Monetário Internacional (FMI) e o Banco Mundial (BM). Para efetivar as reformas, sobretudo da educação profissional, o Governo Federal lançou um conjunto de medidas legais que visavam a alterações significativas na institucionalidade da educação profissional e, de forma mais específica, da Rede Pública Federal.

Um dos preceitos sustentadores das reformas foi desvincular o ensino médio do técnico, sob a alegação de que se tratavam de cursos caros e elitizados, especialmente os oferecidos pela Rede Federal. Lima Filho (2002) aponta que, segundo as orientações dos organismos internacionais, os cursos ofertados pela Rede Federal, além de duração muito longa, não atendiam às demandas dos setores produtivos. E ainda, boa parte dos egressos se encaminhava aos estudos no ensino superior, não ingressando de imediato 
no mercado de trabalho, o que afastava a instituição de seu objetivo principal qualificar rapidamente mão de obra para inserção no mercado de trabalho.

Dessa forma, algumas medidas foram apresentadas como solução. Porém a que ganhou maior destaque na política educacional, que viria a ser regulamentada pelos novos instrumentos legais, foi a separação entre ensino médio e ensino técnico e a consequente extinção dos cursos técnicos integrados ao ensino médio. Dentre essas medidas destaca-se:

Em 1996, em Belo Horizonte, o então Ministro da Educação Paulo Renato de Souza anunciou a negociação em curso com o Banco Mundial com vistas à obtenção de recursos para a reforma da educação profissional no país e que isso implicaria a reformulação do ensino profissional, oferecido pela rede de Escolas Técnicas Federais e CEFETs, para que se pudesse oferecer cursos mais rápidos e específicos e separados do ensino regular (FOLHA DE S. PAULO, 1996 apud LIMA FILHO, 2002, p. 116).

Com relação às medidas tomadas para implantação da reforma, Frigotto (2003) afiança que o projeto da nova Lei de Diretrizes e Bases da Educação Nacional (LDBEN, Lei n. ${ }^{\circ}$ 9.394/1996), que tramitava na Câmera Federal, elaborado por mais de 30 organizações educacionais, políticas, sindicais e científicas, integrantes do Fórum em Defesa da Escola Pública, sofreu várias emendas no texto original. Foi uma tentativa de implantar as reformas posteriormente por meio de outros expedientes legislativos, como decretos e portarias.

Esse movimento de construção democrática do texto da nova LDBEN foi atropelado pelo Governo Federal. Frigotto, Ciavatta e Ramos (2005) enfatizam que, paralelamente às discussões acerca da nova LDBEN, o Governo Federal lançou o Projeto de Lei n. ${ }^{\circ}$ 1.603/96, que previa consideráveis modificações na estrutura da educação profissional e na criação de um sistema separado desta, independente da educação regular. Essa separação evidenciava a intenção dos legisladores de não reconhecer o ensino regular como de fundamental importância para a formação do trabalhador. Com isso, propõe-se a formação em larga escala de mão de obra para atender às demandas do mercado de trabalho, colocando a educação profissional aligeirada e desvinculada como alternativa à educação básica integral, que prepara tanto para o trabalho quanto para outros aspectos da vida.

A Lei n. ${ }^{\circ}$ 9.394/1996, que embora tenha sido pioneira no uso da expressão “educação profissional”, não tratou essa modalidade de forma aprofundada. Em seu 
artigo 40 determina que: "A educação profissional será desenvolvida em articulação com o ensino regular ou diferentes estratégias de educação continuada, em instituições especializadas ou no ambiente do trabalho" (BRASIL, 1996).

Para Saviani (1998), a utilização da palavra "articulação", para estabelecer a forma como a educação profissional deveria se relacionar com as outras modalidades de ensino, permitiu as mais diferentes interpretações na aplicação da lei. Segundo o autor, tais indefinições poderiam ter sido intencionais, com o objetivo de deixar espaço aberto para a lei do ensino profissional, que ainda transitava no Congresso Nacional. Esses elementos permitiram ao governo abandonar o Projeto de Lei n. ${ }^{\circ} 1.603 / 1996$, por meio do Decreto n. ${ }^{\circ}$ 2.208/1997 (BRASIL, 1997a), que estabeleceu a separação entre o ensino profissional (técnico) e o ensino propedêutico.

Os textos políticos e legislativos normatizam e dão base de sustentação para que as políticas propostas sejam efetivadas. Nesse caso, no contexto da influência local, onde ocorrem as disputas para influenciar a definição das finalidades sociais da educação, conforme destacado por Frigotto (2003), houve várias emendas ao projeto original da LDBEN que tramitava na Câmera Federal. É nesse lugar que os conceitos ganham validade e dão forma ao discurso que dá embasamento à política.

O Governo Federal lançou um dispositivo para consolidar a reforma da educação profissional: o Decreto n. ${ }^{o}$ 2.208/97, que regulamenta os artigos 39 ao 42 da Lei n. ${ }^{\circ}$ 9.394/96, definindo um conjunto de regras para o desenvolvimento da educação profissional no Brasil.

Nesse mesmo ano o Governo lançou a Portaria n. ${ }^{\circ}$ 646/1997 (BRASIL, 1997b), cujo conteúdo pretendia disciplinar a implantação dos preceitos do Decreto n. ${ }^{\circ}$ 2.208/97 na Rede Federal de Educação Profissional. Com isso, o Governo limitou a oferta de ensino médio nas instituições federais, visto que as escolas não poderiam oferecer mais do que $50 \%$ das suas vagas para o ensino médio (ensino propedêutico), induzindo a abertura de cursos exclusivamente profissionalizantes. A Portaria n. ${ }^{\circ}$ 646/97, em seu artigo 3. ${ }^{\circ}$, define que "as instituições federais de educação tecnológica só poderão manter ensino médio, com matrícula independente da educação profissional, ofertando no máximo 50\% do total de vagas oferecidas em 1997” (BRASIL, 1997b, p. 2). O documento Educação Profissional Técnica de Nível Médio Integrada ao Ensino Médio destaca: 
Na prática, essa simples Portaria determinou a redução da oferta de ensino médio no país - algo flagrantemente inconstitucional, mas que teve plena vigência até 01/10/2003, quando foi publicada no Diário Oficial da União a sua revogação por meio da Portaria $n .^{\circ} 2.736 / 2003$ (BRASIL, 2007, p. 20-21).

O referido documento assevera, ainda, que a manutenção dos $50 \%$ da oferta do ensino médio na Rede Federal não era a intenção inicial dos autores da reforma. A ideia era extinguir terminantemente a vinculação das instituições federais de educação tecnológica com a educação básica. Na realidade, a manutenção desses $50 \%$ foi fruto de um intenso processo de mobilização ocorrido na Rede Federal, na época.

A Rede Federal de Educação Profissional, composta pelos Centros Federais de Educação Profissional e Tecnológica (CEFETs), entre outros, que tinham por tradição a oferta de ensino médio integrado ao profissionalizante, sofreu mudanças radicais em função da nova legislação.

\section{Breve histórico do ensino médio no Brasil}

Kuenzer (2002) enfatiza que no início do século XX, no Brasil, as iniciativas estatais criaram as escolas profissionais (Escolas de Aprendizes e Artífices, em 1909) e só nos anos 1940 criaram o ensino propedêutico, hoje denominado ensino médio. Entretanto não há como compreender a história do ensino médio no Brasil sem relacioná-la com a do ensino profissionalizante.

Conforme sinalizam Mainardes et al. (2011), ao se referir à análise do contexto de uma política específica, é necessário levar em conta os antecedentes históricos, as pressões de fatores econômicos, sociais e políticos que levaram a questão a ser incluída na agenda política. Partindo desse pressuposto, para uma adequada compreensão, faz-se imprescindível uma brevíssima análise do desenvolvimento histórico do ensino médio, ao longo do último século no Brasil.

A história do Ensino Médio no Brasil revela as dificuldades típicas de um nível de ensino que, por ser intermediário, precisa dar respostas à ambigüidade gerada pela necessidade de ser ao mesmo tempo, terminal e propedêutico. Embora tendo na dualidade estrutural a sua categoria fundante, as diversas concepções, que vão se sucedendo ao longo do tempo, refletem a correlação de funções dominantes em cada época, a partir da etapa de desenvolvimento das forças produtivas (KUENZER, 2002, p. 9). 
Esse excerto mostra que, se por um lado a terminalidade faz com que um grande número de estudantes possa sair do sistema escolar mais cedo e, aparentemente, aptos para o mercado de trabalho, por outro o ensino propedêutico proporciona condições para que esses estudantes ingressem no ensino superior. Kuenzer (2002) analisa que o ensino médio no Brasil sempre teve dificuldades para ser compreendido, pois a formação dos trabalhadores e cidadãos do país se caracterizou, historicamente, delimitada pela trajetória educacional diferenciada e permeada por uma dualidade decorrente da estratificação social e da divisão social do trabalho. Assim, as políticas atendem às necessidades dos modos de produção de cada período histórico.

Sobre o ensino médio, Frigotto, Ciavatta e Ramos (2005, p. 7) inferem:

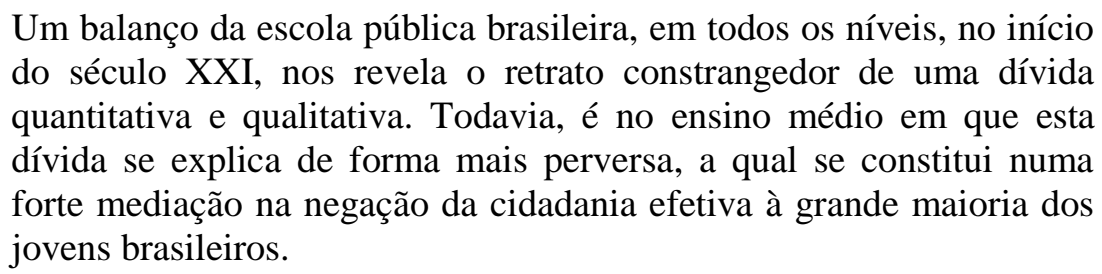

De acordo com os mesmos autores, esse nível educativo tem sua origem na necessidade de formação para a elite, que precisava preparar-se para o acesso ao ensino superior. O atual ensino médio brasileiro passou por um longo percurso até se compor da forma como hoje está estruturado. Ainda no tocante ao ensino médio, Kuenzer (2002, p. 26) afirma:

\begin{abstract}
Assim é que já se tem demonstrado ser a dualidade estrutural a categoria explicativa da constituição do Ensino Médio e profissional no Brasil, já que, desde o surgimento da primeira iniciativa estatal nessa área, até o presente, sempre se constituíram duas redes: uma profissional e outra de educação geral, para atender às necessidades socialmente definidas pela divisão social e técnica do trabalho.
\end{abstract}

Sendo assim, a formação de trabalhadores e cidadãos no Brasil constitui-se a partir de duas redes: a de "formação geral", mais acadêmica e intelectualizada, e a de "formação profissional", voltada para ações instrumentais do próprio trabalho. Todavia não há como entender o ensino médio no Brasil sem tomá-lo em sua relação com o ensino profissional, visto que ambos concebem as duas faces, que deveriam ser inseparáveis, da mesma proposta: a formação de intelectuais e de operacionais da força produtiva. 
Em 1942 houve a Reforma Capanema, a qual reformulou alguns ramos do ensino, por iniciativa do então Ministro da Educação, Gustavo Capanema. Tais reformas são denominadas Leis Orgânicas do Ensino. Conforme o Decreto n. ${ }^{\circ}$ 4.244/42, com a Promulgação das Leis Orgânicas, extinguiram-se os chamados cursos complementares, que eram realizados nas próprias escolas de nível superior, tinham dois anos de duração e eram destinados aos que concluíram a 5. ${ }^{a}$ série do curso ginasial. Esses cursos secundários eram conhecidos como: a) colegiais, os quais se denominavam clássico e científico, com o objetivo de preparar para o ensino superior; b) cursos profissionalizantes - normal, agrotécnico, comercial técnico e industrial técnico, que correspondiam ao mesmo nível educativo. Porém não possibilitavam o acesso ao ensino superior (ROMANELLI, 2001).

Em 1961 a LDB n. ${ }^{\circ} 4.024$ (BRASIL, 1961) equiparou a educação profissional ao ensino acadêmico. Com a promulgação dessa lei, demonstra-se, pela primeira vez, a articulação completa entre os ramos do $2 .^{\circ}$ ciclo e profissional para fins de elevação ao ensino superior. Portanto, foi realizada a plena equivalência entre todos os cursos do mesmo nível, sem a obrigatoriedade de exames e provas de conhecimentos para acessar ao nível superior.

Na década de 1970 instituiu-se a LDB n. ${ }^{\circ} 5.692$ (BRASIL, 1971), que substituiu a equivalência entre os ramos secundário e propedêutico pela obrigatoriedade da habilitação profissional para todos os que cursassem, o que passou a ser chamado de ensino de $2 .^{\circ}$ grau. Ao estabelecer um currículo único para todos os estudantes desse nível de ensino, independentemente de estratificação social, a Lei n. ${ }^{\circ}$ 5.692/71 sugeria a eliminação da dualidade observada até então entre o ensino profissionalizante e o ensino propedêutico.

Se a Lei n. ${ }^{\circ}$ 4.024/61 apontava mudanças no sentido de unificar o ensino profissionalizante e propedêutico, a Lei n. ${ }^{\circ} 5.692 / 71$ inaugurou um novo panorama. Todo o ensino médio foi instituído "profissionalizante" de modo compulsório.

Kuenzer (2002) enfatiza que a profissionalização compulsória do ensino médio (2. ${ }^{\circ}$ grau) foi alterada pela Lei $n .^{\circ} 7.044 / 82$, que extinguiu a escola única de profissionalização obrigatória, a qual nunca chegou a existir concretamente. Essa lei reedita a concepção vigente antes de 1971, de uma escola dualista (propedêutica e profissionalizante).

O período que se iniciou após a promulgação da Constituição Brasileira de 1988 caracteriza-se por reformas políticas, observadas não só no Brasil, como também em 
outros países da América Latina. As reformas foram promovidas sob fortes influências dos organismos multilaterais, como Organização das Nações Unidas para a Educação, a Ciência e a Cultura (UNESCO), que organizou a Conferência Mundial de Educação para Todos, em 1990, em Jomtien (Tailândia), e produziu, de 1993 a 1996, o Relatório Delors (coordenado por Jacques Delors), que fez um diagnóstico do contexto planetário e analisou os desafios para a educação no século XXI, além da Comissão Econômica para a América Latina e Caribe (CEPAL), com os programas Transformacion Productiva con Equidad (1990) e Educacion y Conocimiento: Eje de La Transformacion Productiva con Equidade (1992) (NASCIMENTO; QUIRINO, 2013, p. 85). Como resultado, as reformas políticas e econômicas deram uma nova configuração à sociedade brasileira. O início da década de 1990 marcou a introdução de mudanças estruturais no Brasil.

Autores como Castro, Mello e Souza (1997) defendem a ideia de separar o ensino acadêmico do profissional e afiançam que o ensino médio e o técnico existentes apresentavam problemas relativos à dualidade, à falta de identidade e à ausência de qualidade. Segundo os autores (1997, p. 7), “o ethos da escola acadêmica mata a profissionalização, sobretudo nas ocupações industriais - cheias de graxa e serragem". Para eles, as escolas técnicas industriais e os CEFETs eram dispendiosos em suas estruturas, pois se transformaram em caminhos privilegiados para o vestibular em vez de ocuparem-se com a formação para o mercado de trabalho imediato.

Por outro lado, para Kuenzer (2002), tal modalidade - ensino profissional de nível médio - é fundamental, pois, para a maioria dos jovens exercer um trabalho, muitas vezes o curso profissionalizante seria a única alternativa para continuar seus estudos em nível superior. O ensino médio, desse modo, para atender os jovens menos favorecidos, deveria responder aos desafios de atender às duas demandas: o acesso ao trabalho e a continuidade dos estudos.

\section{Os impactos da desvinculação do ensino médio profissionalizante e propedêutico na visão dos professores}

Nas entrevistas realizadas com professores que atuam no IFSC - Campus Jaraguá do Sul, sobre a nova configuração da educação profissional a partir da desvinculação entre o ensino médio e técnico, na década de 1990, os entrevistados assim aludem: 
Acho assim, foi toda uma política de deixar mais a coisa para o mercado. Era bem diferente, quer dizer, da formação do ensino médio integrado, o que interessava era formar mão de obra rapidamente (Entrevistado A).

No final da década de 90, com o Decreto $n .^{\circ} 2.208$, a reforma definia que a gente tinha que jogar para o mercado mão de obra qualificada de forma mais rápida. Muito bem, como fazer isso? Primeiro, vamos acabar com o ensino médio dentro das escolas técnicas (Entrevistado F).

Os entrevistados referem-se às novas determinações advindas do Decreto $\mathrm{n}^{\circ}$ 2.208/97 e de outros instrumentos legais, como a Portaria n. ${ }^{\circ}$ 646/97, que "vem não somente proibir a pretendida formação integrada, mas regulamentar formas fragmentadas e aligeiradas de educação profissional em função das alegadas necessidades do mercado" (FRIGOTTO; CIAVATTA; RAMOS, 2006, p. 25).

Outros entrevistados se referem à formação voltada para atender aos objetivos do capital:

O decreto veio para deixar tudo como estava, ou seja, a Rede Federal, de novo, estava atendendo aos objetivos do grande capital, do mercado. Só que não era mais uma mão de obra sem nenhuma qualificação, teria que ser uma mão de obra com um mínimo de qualificação, porque a globalização estava exigindo um avanço técnico, tecnológico (Entrevistado I).

Preparação para o trabalho, a impressão que dava é que o importante era que eles soubessem fazer e não o fazer pensado. O objetivo para o mercado de trabalho é que eles soubessem fazer, produzir, produzir (Entrevistado G).

Os entrevistados aludem à nova modalidade de ensino como sendo específica para atender ao mercado de trabalho, que passa a exigir uma certa qualificação da mão de obra para acatar as finalidades do grande capital. Observa-se, na fala do Entrevistado G, que para o Estado o ensino deveria propiciar uma qualificação para o "fazer", “produzir”, sem a necessidade de preparar para um agir crítico, de tomada de decisão, de capacidade de resolução de problemas, o que acarretaria na manutenção da estrutura de uma sociedade capitalista.

A reforma constituiu um "ajuste estrutural requerido pela dinâmica das relações capital/trabalho na economia política da globalização" (LIMA FILHO, 2002, p. 167). Sendo assim, o Governo Federal aceitou o modelo de desenvolvimento prescrito pelos 
organismos internacionais, promovendo os ajustes necessários estabelecidos por aquelas organizações.

Sobre a análise das políticas, bem como a reflexão sobre suas possibilidades, Mainardes (2007, p. 50) infere: “[...] os profissionais que atuam nas escolas não são totalmente excluídos dos processos de formulação ou implementação de políticas [...]”. Desse modo, o que o corpo docente pensa, assim como o que planeja e exercita a partir disso, tem influência direta no processo de implementação das políticas públicas educacionais.

No contexto da prática os professores participam ativamente da implantação dessa política educacional, pois, ao interpretar o texto político no cotidiano escolar, podem apresentar práticas diferentes, que não surgiram no ideário de quem escreveu/produziu o texto político.

As instituições da Rede Federal de Educação Profissional ofertavam cursos técnicos integrados ao ensino médio. O câmpus Jaraguá do Sul do IFSC também ofertava tais cursos integrados, nas áreas de Eletromecânica e Têxtil. Com o advento do Decreto n. ${ }^{\circ}$ 2.208/97, teve de se adequar à nova realidade, desvinculando o ensino médio do técnico e ofertando cursos em forma de módulos, sistematicamente organizados para o desenvolvimento de competências profissionais. Os entrevistados relatam como ocorreu tal processo:

\footnotetext{
O Pós-Médio é uma formação só da parte técnica para o cidadão, ele vem aqui e recebe essa série de informações técnicas com carga horária bem reduzida (Entrevistado A).
}

Primeiro uma carga horária, bem reduzida às disciplinas técnicas, preparação para o trabalho [...] o curso era só de 1.200 horas. Antes de 97, quando nós tínhamos o integrado, ele tinha uma quantia de disciplinas técnicas bastante superior. Superior do que as 1.200 horas, então, quer dizer: ele fazia um desenho de informática básica depois fazia outra informática, uma formação mais ampla e uma maior carga horária (Entrevistado D).

A fala dos professores evidencia que as determinações da Reforma da Educação Profissional provavelmente acarretaram a queda da qualidade do ensino em virtude da extinção da integração entre educação geral e educação profissional, além da redução da carga horária. A referida integração constituía um dos fatores responsáveis pela qualidade do ensino técnico, pois procurava garantir uma sólida formação geral, 
conforme apontado pelo Entrevistado D, que se pode definir como pré-requisito de uma educação de qualidade.

Com relação à Reforma Profissional advinda de marcos regulatórios nacionais,

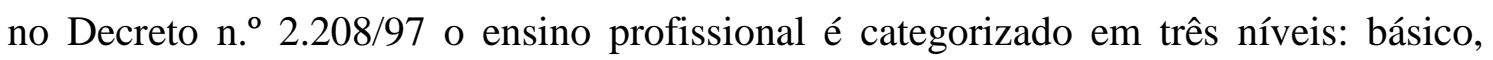
técnico, tecnológico, conforme enunciado no artigo $3 .^{\circ}$ :

Art. 3. ${ }^{\circ}$ - A educação profissional compreende os seguintes níveis: I - básico: destinado à qualificação, requalificação e reprofissionalização de trabalhadores, independente de escolaridade prévia;

II - técnico: destinado a proporcionar habilitação profissional a alunos matriculados ou egressos do ensino médio, devendo ser ministrado na forma estabelecida por este Decreto;

III - tecnológico: correspondente a cursos de nível superior na área tecnológica, destinados a egressos do ensino médio e técnico (BRASIL, 1997a, p. 1).

Ainda sobre a nova organização curricular por módulos, na forma subsequente ao ensino médio, o Entrevistado I infere:

Os nossos alunos eram alunos já adultos, mais de 90\% trabalhadores. Muitos deles vinham de supletivo, atual EJA [educação de jovens e adultos], de educação descontinuada e necessitavam mesmo de um reforço das disciplinas da cultura geral, ou seja, matemática, português, química e física; eram matérias que eles precisavam rever, e acho até ver. Alguns nem tinham tido essas matérias com a devida profundidade para poderem assimilar as disciplinas técnicas que viriam a seguir. Quem é que vai aprender eletricidade sem uma matemática e uma física bem dadas? É quase impossível. Então, realmente, para Jaraguá, fazia uma diferença bem grande (Entrevistado I).

Na fala do Entrevistado I, nota-se a preocupação com a formação profissional, entendendo que a formação geral é imprescindível para a apreensão dos conteúdos relacionados à profissionalização.

No entanto uma das justificativas defendidas pelo Governo Federal para separar o ensino médio do técnico foi a de que a educação profissional era utilizada para formar os estudantes para o vestibular, pois eles, muitas vezes, faziam apenas o ensino médio na Rede Federal e direcionavam-se para o ensino superior. Essa justificativa não se sustenta, pois, como dito pelo Entrevistado I, os conhecimentos gerais podem estar incluídos na formação profissional. Com outra visão esse argumento também foi elencado pelo Entrevistado F, que assim se manifesta: 
Primeiro, vamos acabar com o ensino médio dentro das escolas técnicas, porque o ensino médio, segundo a visão do Governo da época, só formava para o vestibular, não estava formando mão de obra, como eles queriam, para o mercado [...]. Nossa realidade, aqui, não era essa, porque a gente tinha uma mistura de alunos de várias idades com várias condições e que não era bem assim. $O$ ensino técnico de nível médio não era apenas um trampolim para o superior (Entrevistado F).

Os entrevistados enfatizaram que, em Jaraguá do Sul, a realidade não era igual à retratada na argumentação oficial. Por ser o Brasil um país gigantesco em extensão, nem sempre as políticas públicas construídas para o macro contemplam as microrregiões, ou seja, as regiões mais distantes dos grandes centros.

Diante da análise das entrevistas, pode-se inferir que esses processos impactaram de maneira significativa na qualidade da formação ali ofertada e que toda a política pública implica mudanças nem sempre significativas para todos em todos os lugares.

\section{Algumas considerações}

Considerando os resultados obtidos por meio das entrevistas a respeito da Reforma da Educação Profissional, além da redução de vagas no ensino médio, a pesquisa apontou dificuldades vivenciadas na implementação da política pública em questão.

Chega-se à conclusão de que essa política pública contribuiu de maneira significativa para a diminuição da oferta de vagas públicas e gratuitas do ensino médio na referida instituição. As determinações da Reforma da Educação Profissional acarretaram a queda da qualidade do ensino em decorrência da extinção da integração entre educação geral e educação profissional. As políticas públicas deveriam também responder aos desafios de atender a duas demandas: o acesso ao trabalho e a continuidade dos estudos.

Ao implementar tais políticas, as intenções do Governo do então Presidente Fernando Henrique Cardoso estiveram centradas numa ideia de desenvolvimento para o país baseada na economia global e, ao mesmo tempo, sustentada por uma conduta neoliberal, de submissão às regras internacionais de mercado.

Assim, como as demais instituições da Rede Federal, a então UnED/JS da ETF/SC ofertava cursos de ensino médio integrado ao profissionalizante desde o início de seu funcionamento, em 1994. Porém a instituição foi "impactada" diretamente pelo Decreto n. $.^{\circ} 2.208 / 97$, que não mais aceitava a oferta do ensino técnico integrado ao 
ensino médio.

Na Unidade de Ensino de Jaraguá do Sul, hoje câmpus Jaraguá do Sul do IFSC, eram ofertados dois cursos: um na área Têxtil e outro em Eletromecânica. Essa instituição também precisou se adequar à nova legislação, ou seja, desvincular o ensino médio de seus cursos técnicos. As instituições federais ficaram incumbidas de ofertar cursos com menor duração (carga horária reduzida), especificamente para atender ao mercado, a serviço do grande capital.

O ensino médio integrado ao profissionalizante configura-se um curso geralmente muito procurado e importante, por se tratar da formação integral do jovem que adentrará no mundo do trabalho, pois, para a maioria deles, desempenhar um trabalho técnico poderá ser a única opção para prosseguir seus estudos em uma universidade e conquistar um trabalho mais qualificado. Não ofertá-lo seria desprover essa população do acesso a uma melhor qualificação (KUENZER, 2002).

Diante disso, entende-se que uma administração pública, que considere sua função de atender a sociedade indistintamente, deveria estabelecer políticas públicas que supram as necessidades de toda a sociedade, possibilitando-lhe o acesso a uma educação que vise à reversão do desequilíbrio social.

Com base nos resultados da presente pesquisa, cuja base foi a análise de conteúdo por meio de entrevistas, a implementação das políticas públicas da educação profissional na década de 1990 pode ter impactado negativamente na educação ofertada na instituição estudada.

Toda mudança nos rumos da política educacional pode trazer transtornos, seja por parte dos atores envolvidos, seja pela sua implementação. Por isso, tal mudança precisa ser acompanhada, analisada, e ainda seria importante verificar os impactos que ela produz, especialmente os efeitos na formação do estudante, se foram positivos ou negativos, além da possibilidade de correções ou adequações.

Importante finalizar que o assunto não se esgota aqui, haja vista as políticas públicas estarem sempre em movimentos contínuos de ressignificação. Espera-se, portanto, que as informações e reflexões apresentadas neste artigo possam contribuir nos contextos das instituições federais, no sentido de pensar que na implantação de uma lei ou qualquer outro documento legal é fundamental analisar o cenário e a latência dos movimentos. Também se faz necessário refletir sobre a relação das políticas públicas com o tempo em que foram concebidas, entendendo que é imprescindível readequá-las, reavaliá-las e ressignificá-las sempre que for preciso. Esse é o movimento das políticas 
públicas.

\section{Referências}

BARDIN, L. Análise de conteúdo. Tradução de Luís Antero Reto e Augusto Pinheiro. 2. ${ }^{a}$ reimp. São Paulo: Edições 70, 2011.

BRASIL. Decreto n. ${ }^{\circ}$ 2.208, de 17 de abril de 1997. Regulamenta o $§ 2 .^{\circ}$ do artigo 36 e os artigos 39 a 42 da Lei 9.394, de 20 de dezembro de 1996. Brasília, 1997a. Disponível em: <http://www.planalto.gov.br/ccivil_03./decreto/D2208.htm>. Acesso em: 12 fev. 2014.

BRASIL. Decreto n. ${ }^{\circ}$ 2.208, de 17 de abril de 1997. Educação profissional técnica de nível médio integrada ao ensino médio. Documento base. Brasília, 2007.

BRASIL. Decreto n. ${ }^{\circ}$ 2.208, de 17 de abril de 1997. Lei n. ${ }^{\circ} 4.024$, de 20 de dezembro de 1961. Fixa as Diretrizes e Bases da Educação Nacional. Brasília, 1961. Disponível em: <http://www.planalto.gov.br/ccivil_03/leis/14024.htm>. Acesso em: 10 fev. 2014.

BRASIL. Decreto n. ${ }^{\circ}$ 2.208, de 17 de abril de 1997. Lei n. $^{\circ}$ 5.692, de 11 de agosto de 1971. Lei de Diretrizes e Bases. Fixa Diretrizes e Bases para o ensino de $1 .^{\circ}$ e $2 .^{\circ}$ graus. Brasília, 1971. Disponível em: 〈http://www.camara.gov.br〉. Acesso em: 1. ${ }^{\circ}$ fev. 2014.

Lei n. 9.394, de 20 de dezembro de 1996. Lei de Diretrizes e Bases da Educação Nacional. Brasília, 1996. Disponível em: <http:////portal.mec.gov.br/seb/arquivos/pdf/ldb.pdf>. Acesso em: 30 jan. 2014.

BRASIL. Decreto n..$^{\circ}$ 2.208, de 17 de abril de 1997. Portaria n. ${ }^{\circ}$ 646, de 14 de maio de 1997. Regulamenta a implantação do disposto nos artigos 39 a 42 da Lei Federal n. ${ }^{\circ}$ 9.394/96 e no Decreto n. ${ }^{\circ}$ 2.208/97 e dá outras providências. Brasília, 1997b. Disponível em: <http://www.planalto.gov.br〉. Acesso em: 12 fev. 2014.

CASTRO, C. de M.; MELlO E SOUZA, A. O secundário esquecido em um desvão do ensino? Textos para Discussão, Brasília, v. 1, n. 2, abr. 1997.

FRIGOTTO, G. Educação e a crise do capitalismo real. 5. ed. São Paulo: Cortez, 2003.

FRIGOTTO, G. Fundamentos científicos e técnicos da relação trabalho e educação no Brasil de hoje. In: LIMA, J. C. F.; NEVES, L. M. W. (Orgs.). Fundamentos da educação escolar do Brasil contemporâneo. Rio de Janeiro: Fiocruz, 2006.

FRIGOTTO, G; CIAVATTA, M.; RAMOS, M. Concepção e mudanças no mundo do trabalho e o ensino médio. In: FRIGOTTO, G. et al. (Orgs.). Ensino médio integrado: concepções e contradições. São Paulo: Cortez, 2005.

HÖFLING, E. de M. Estado e políticas (públicas) sociais. Cadernos Cedes, Campinas, ano XXI, n. ${ }^{\circ}$ 55, 2001. 
KUENZER, A. Z. Ensino médio: construindo uma proposta para os que vivem do trabalho. 3. ed. São Paulo: Cortez, 2002.

LIMA FILHO, D. L. A reforma da educação profissional no Brasil nos anos noventa. Tese (Doutorado em Educação)-Faculdade de Educação, Universidade Federal de Santa Catarina, Florianópolis, 2002.

LIMA FILHO, D. L. Condicionantes do financiamento internacional do ensino técnico: a história dos CEFETs e a origem do modelo alternativo de ensino superior não universitário. In: Congresso Brasileiro de História da Educação: A Educação Escolar em Perspectiva Histórica, 3., 2004. Anais.... Disponível em: <http://www.sbhe.org.br/novo/congressos/cbhe3/paginas/cbhe.htm>. Acesso em: 15 jan. 2014.

MAINARDES, J. Abordagem do ciclo de políticas: uma contribuição para a análise de políticas educacionais. Educação e Sociedade, Campinas, v. 27, n. 94, p. 47-69, jan./abr. 2006. Disponível em: <http://www.cedes.unicamp.br>. Acesso em: 7 jan. 2014.

MAINARDES, J. Reinterpretando os ciclos de aprendizagem. São Paulo: Cortez, 2007.

MAINARDES, J et al. Análise de políticas: fundamentos e principais debates teóricometodológicos. In: BALL, S. J.; MAINARDES, J. (Orgs.). Políticas educacionais: questões e dilemas. São Paulo: Cortez, 2011.

NASCIMENTO, W. B.; QUIRINO, R. A educação profissional e tecnológica após o processo de "ifetização": da identidade institucional à autonomia administrativa. Disponível em: <http://www.senept.cefetmg.br/galerias/Anais_2012/GT-03/GT03033.pdf>. Acesso em: 14 jan. 2013.

ROMANELli, O. de O. História da educação no Brasil. 25. ed. Rio de Janeiro: Vozes, 2001.

SAVIANI, D. Da nova LDB ao Novo Plano Nacional de Educação: por uma outra política educacional. Campinas: Autores Associados, 1998.

\section{Como referenciar este artigo}

MORAES, Laurinda Ines Souza de.; PILLOTTO, Silvia Sell Duarte.; VOIGT, Jane Mery Richter. Políticas públicas para educação profissional: década de 1990 e a desvinculação do ensino médio e técnico. Revista on line de Política e Gestão Educacional, Araraquara, v.21, n.1, p. 108-124, 2017. Disponível em: <http://dx.doi.org/10.22633/rpge.v21.n.1.2017.9784>. ISSN: 1519-9029.

Submetido em: 10/01/2017

Aprovado em: 30/03/2017 